OPEN ACCESS

Edited by:

Axel Schippers,

Federal Institute for Geosciences and Natural Resources, Germany

Reviewed by:

Sunita R. Shah Walter, Harvard University, USA

Jeannette Marrero-Coto,

Leibniz University of Hanover

Germany

*Correspondence: Philippe M. Oger poger@ens-lyon.fr

Specialty section: This article was submitted to Extreme Microbiology, a section of the journal

Frontiers in Microbiology

Received: 10 July 2015 Accepted: 05 October 2015 Published: 21 October 2015

Citation:

Cario A, Grossi V, Schaeffer $P$ and Oger PM (2015) Membrane

homeoviscous adaptation

in the piezo-hyperthermophilic archaeon Thermococcus barophilus.

Front. Microbiol. 6:1152. doi: 10.3389/fmicb.2015.01152

\section{Membrane homeoviscous adaptation in the piezo-hyperthermophilic archaeon Thermococcus barophilus}

\author{
Anaïs Cario ${ }^{1}$, Vincent Grossi ${ }^{1}$, Philippe Schaeffer ${ }^{2}$ and Philippe M. Oger ${ }^{1 *}$ \\ ${ }^{1}$ CNRS, Laboratoire de Géologie de Lyon, Ecole Normale Supérieure de Lyon, UMR 5276, Université Claude Bernard \\ Lyon 1, Lyon, France, ${ }^{2}$ CNRS, Laboratoire de Biogéochimie Moléculaire, Institut de Chimie de Strasbourg, Ecole de Chimie, \\ Polymères et Matériaux, UMR 7177, Université de Strasbourg, Strasbourg, France
}

The archaeon Thermococcus barophilus, one of the most extreme members of hyperthermophilic piezophiles known thus far, is able to grow at temperatures up to $103^{\circ} \mathrm{C}$ and pressures up to $80 \mathrm{MPa}$. We analyzed the membrane lipids of T. barophilus by high performance liquid chromatography-mass spectrometry as a function of pressure and temperature. In contrast to previous reports, we show that under optimal growth conditions $\left(40 \mathrm{MPa}, 85^{\circ} \mathrm{C}\right)$ the membrane spanning tetraether lipid GDGT-0 (sometimes called caldarchaeol) is a major membrane lipid of T. barophilus together with archaeol. Increasing pressure and decreasing temperature lead to an increase of the proportion of archaeol. Reversely, a higher proportion of GDGT-0 is observed under low pressure and high temperature conditions. Noticeably, pressure and temperature fluctuations also impact the level of unsaturation of apolar lipids having an irregular polyisoprenoid carbon skeleton (unsaturated lycopane derivatives), suggesting a structural role for these neutral lipids in the membrane of T. barophilus. Whether these apolar lipids insert in the membrane or not remains to be addressed. However, our results raise questions about the structure of the membrane in this archaeon and other Archaea harboring a mixture of di- and tetraether lipids.

\footnotetext{
Keywords: archaeal lipids, archaeal membrane, homeoviscous adaptation, piezophily, deep-biosphere, GDGT-0, archaeol, Thermococcus barophilus
}

\section{INTRODUCTION}

Biological membranes act as barriers to solute diffusion, and play a central role in energy storage and processing via ion gradients. Maintaining optimal membrane function is therefore crucial for the cell. Under physiological conditions, membranes are relatively fluid, disordered liquidcrystalline phases. Perturbations in lipid phase state have profound consequences on membrane structure and function (Lee, 2003, 2004), i.e., clustering of membrane proteins, reduction of membrane protein activity, reduced solute fluxes, or increased permeability to cations and water. Thus, fluctuations of environmental conditions such as variations in temperature, salinity, hydrostatic pressure, or $\mathrm{pH}$ pose serious challenges to cells (Hazel, 1995). Based upon the observation that membrane lipids of Escherichia coli grown under contrasting temperatures were different (Marr and Ingraham, 1962; Sinensky, 1971) but exhibited almost identical physical properties, Sinensky (1974) established the basis of homeoviscous adaptation. This theory states that membrane lipid composition of an organism varies in order to favor the maintenance of an optimal functionality of the membrane. The main membrane adaptation strategies in bacteria 
include: (1) the regulation of fatty acid chain length; (2) the regulation of the degree of unsaturation of fatty acids; (3) the regulation of lipid polar headgroups; or (4) the regulation of the proportion of branched fatty acids (Russell and Nichols, 1999). Each of these modifications can shift the phase transition temperature by up to $20^{\circ} \mathrm{C}$ (Winter, 2002). Thus, by modifying the lipid composition of its membrane, the cell can adapt and maintain its membrane fluidity in a range suitable with its various functions under changing environmental conditions.

Hydrothermal vents discharge high temperature mineralrich waters (up to $350^{\circ} \mathrm{C}$ ) into the surrounding cold ocean $\left(2-4^{\circ} \mathrm{C}\right)$, defining harsh environments characterized by steep physicochemical gradients in $\mathrm{pH}(3-8)$, salinity $(\sim 3-7 \% \mathrm{NaCl})$ and temperature $\left(2-350^{\circ} \mathrm{C}\right)$, in which it is expected that organisms exert a strong resistance to various and multiple stresses. In the deepest part of the oceans, the vent systems are also submitted to high hydrostatic pressures (HHPs) reaching up to $41 \mathrm{MPa}$ at the Ashadze vent site (Zeng et al., 2009). Despite these contrasted environmental conditions, a large diversity of thermophilic and hyperthermophilic prokaryotes has been described, among which hyperthermophilic Archaea from the order Thermococcales often dominate (Flores et al., 2011, 2012). Isolates from deep sites demonstrate a clear adaptation to high pressure. Membranes of deep-sea vent organisms are thus expected to be adapted to the physicochemical conditions encountered in these ecosystems, but little is known about how their membrane lipid composition is modified in response to fluctuations of these conditions.

Unlike bacterial lipids, archaeal lipids are composed of phytanyl and/or biphytanyl hydrocarbon chains linked to glycerol by ether bonds, which confer increased rigidity, thermal stability, and reduced permeability to archaeal membranes (Mathai et al., 2001). The diether phospholipid archaeol [2,3di-O-phytanyl-sn-glycerol (DPG)] is frequent in Archaea and is the dominant or sole core lipid in some extreme halophilic Archaea where it forms bilayer membranes (Gibson et al., 2005; Xue et al., 2005; Minegishi et al., 2010). Thermophilic and hyperthermophilic Archaea often present bipolar membranespanning tetraether lipids which form monolayer instead of bilayer membranes (De Rosa and Gambacorta, 1988). The most common bipolar core lipid is glycerol-dibiphytanyl glycerol tetraether (GDGT-0; sometimes called caldarchaeol). Bipolar lipids pack more tightly than archaeol-based bilayer membranes to form membranes with increased rigidity and low proton leakage at high temperature and acidic pH (Hanford and Peeples, 2002). Homeoviscous adaptation in Archaea has mostly been studied in response to temperature or $\mathrm{pH}$ stresses (Oger and Cario, 2013). In strains harboring mixed diphytanyl diether and dibiphytanyl tetraether lipids, the diether-to-tetraether lipid ratio $(\mathrm{D} / \mathrm{T})$ has been shown to vary with both stresses (Sprott et al., 1991; Lai et al., 2008; Matsuno et al., 2009; Boyd et al., 2011). For instance, in Thermococcus kodakarensis, this ratio decreases from $64 \%$ at $60^{\circ} \mathrm{C}$ to $34 \%$ at $93^{\circ} \mathrm{C}$ (Matsuno et al., 2009). A second mechanism in the homeoviscous adaptation of archaeal membranes involves the regulation of the number of cyclopentane rings in the biphytane hydrocarbon chains of GDGT-0 as a response to $\mathrm{pH}$ or temperature variations
(De Rosa et al., 1980a; Sugai et al., 2000; Boyd et al., 2011; Oger and Cario, 2013), which increases the packing efficiency of membrane lipids (Gliozzi et al., 1983; Gabriel and Chong, 2000), and consequently increases membrane stability and lowers permeability (Chong et al., 2012). Archaea may also increase the proportion of unsaturated lipids to adapt to temperature variations as seen in Methanococcoides burtonii, which accumulates unsaturated archaeol derivatives in response to a lowering in temperature (Nichols et al., 2004). Finally, a fourth adaptive route was observed in Methanocaldococcus jannaschii, a methanogen isolated from a deep-sea vent, in which an increase in temperature induces the accumulation of a crosslinked archaeol derivative, called macrocyclic archaeol (Sprott et al., 1991; Kaneshiro and Clark, 1995), along with an increase in GDGT-0. However, the report of the diether lipid archaeol as sole core lipid in the deep-sea hyperthermophiles such as Methanopyrus kandleri (Hafenbradl et al., 1996) or Thermococcus barophilus (Marteinsson et al., 1999) suggests that alternative homeoviscous mechanisms may exist in Archaea and may play a significant role in the stability and the functionality of archaeal membranes under thermal, $\mathrm{pH}$, or high pressure stresses.

To investigate this point, we have characterized the membrane lipid composition of the model piezo-hyperthermophilic archaeon T. barophilus grown under controlled temperature and pressure. We demonstrate that GDGT-0 is a major core lipid in T. barophilus, in contrast to previous reports (cf. Marteinsson et al., 1999). We further show that homeoviscous adaptation of the membrane in $T$. barophilus involves the regulation of the D/T ratio, as previously reported for other Thermococcales, but also the regulation of the unsaturation level of apolar lipids (unsaturated lycopane derivatives).

\section{MATERIALS AND METHODS}

\section{Microorganism and Growth Conditions}

Thermococcus barophilus strain MP has been isolated from the Snake Pit hydrothermal vent located on the Mid-Atlantic Ridge at a water depth of $3550 \mathrm{~m}$ (Marteinsson et al., 1999). Strain MP displays optimal pressure $(\mathrm{P})$, temperature $(\mathrm{T})$, and salinity at $40 \mathrm{MPa}, 85^{\circ} \mathrm{C}$ and $3 \%$ of $\mathrm{NaCl}$, respectively. Cells were grown under strict anaerobiosis in $200 \mathrm{ml}$ of Thermococcales rich medium (TRM; Zeng et al., 2009) supplemented with 1\% of polysulfide (from a $0.05 \mathrm{mM}$ stock solution; Ikeda et al., 1972). Cultures grown under HHP were carried out in polyethylene bags whereas cultures grown at atmospheric pressure were performed in $500 \mathrm{ml}$ flasks. The effect of $\mathrm{P}$ or $\mathrm{T}$ on the lipid composition of $T$. barophilus strain MP was evaluated. The cultures were grown under five different conditions: (i) optimal $\mathrm{P}$ and $\mathrm{T}$ (40 $\mathrm{MPa} / 85^{\circ} \mathrm{C}$; OPT); (ii) sub-optimal P $\left(0.1 \mathrm{MPa} / 85^{\circ} \mathrm{C}\right.$; LP); (iii) sub-optimal T (40 MPa $/ 75^{\circ} \mathrm{C}$; LT); (iv) supra-optimal P (70 $\mathrm{MP} / 85^{\circ} \mathrm{C}$; HP) and supra-optimal $\mathrm{T}\left(40 \mathrm{MPa} / 90^{\circ} \mathrm{C}\right.$; HT). The experiments were run in triplicate. To increase experimental reproducibility, all cultures were inoculated with $0.5 \%(\mathrm{v} / \mathrm{v})$ of a pre-culture grown under optimal conditions to a final concentration of $1.10^{6}$ cells $\mathrm{ml}^{-1}$. Cell biomass and growth phase were monitored by direct cell counts in a Thoma Chamber 


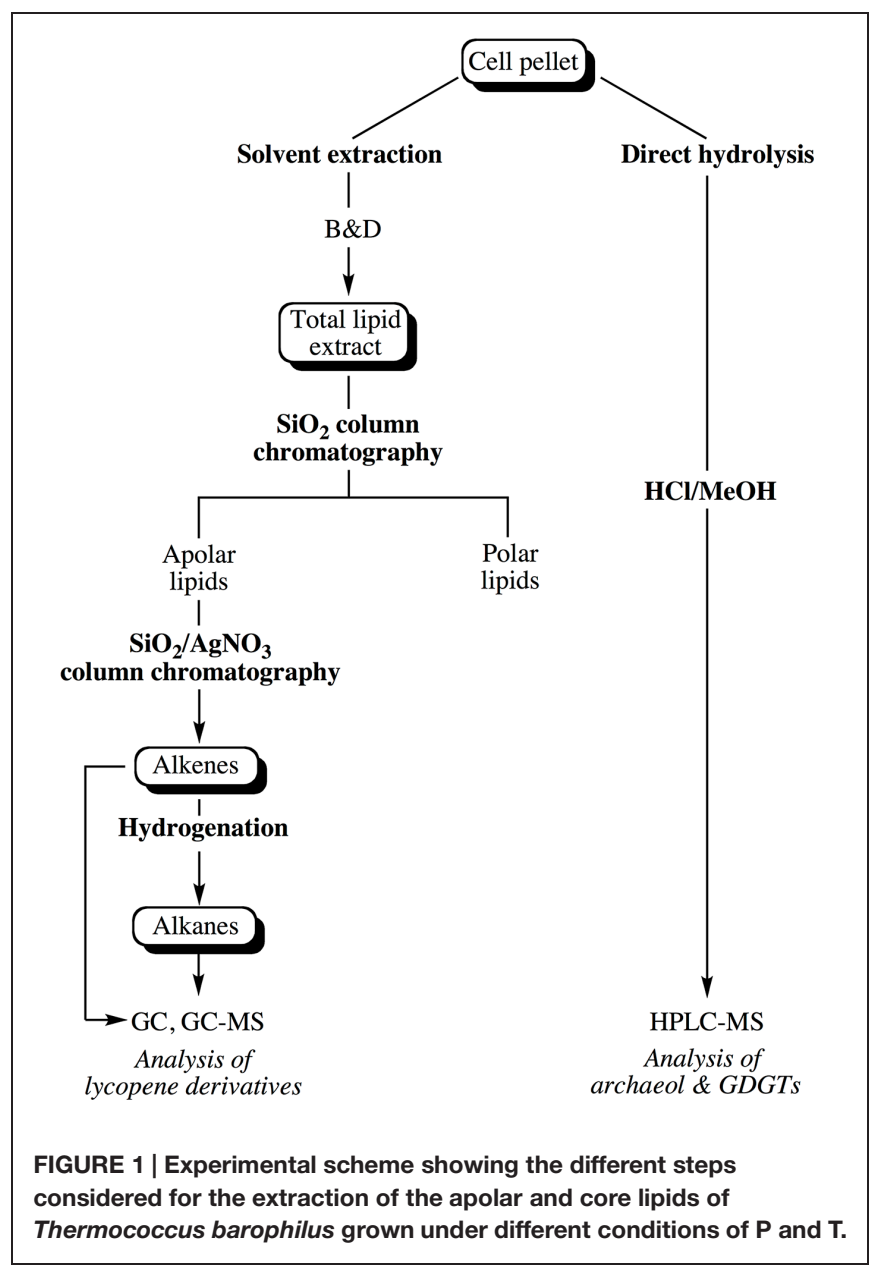

(depth, $0.01 \mathrm{~mm}$ ) using a light microscope (BX41, Olympus, France).

\section{Lipid Extraction}

Lipids were extracted from pellets of cells in late exponential phase harvested by centrifugation $\left(10000 \times g, 4^{\circ} \mathrm{C}\right.$ for $\left.20 \mathrm{~min}\right)$ and washed once with an isotonic solution $(3 \% \mathrm{NaCl})$. The cell pellet was subsequently split into two equal parts in order to extract core lipids and apolar lipids from comparable numbers of cells. The general scheme depicting the extraction and purification of the different classes of lipids is shown in Figure 1.

\section{Core Lipid Extraction}

Core lipids of $T$. barophilus were prepared by direct acidhydrolysis of half of the cell pellet. Cells were placed in a Pyrex tube, resuspended in a $10 \% \mathrm{HCl}-\mathrm{Methanol}(\mathrm{MeOH})$ solution, and baked for $2 \mathrm{~h}$ at $110^{\circ} \mathrm{C}$. After cooling, the $\mathrm{pH}$ of the solution was adjusted to 5.0 with $2 \mathrm{~N} \mathrm{KOH} / \mathrm{MeOH}(1: 1, \mathrm{v} / \mathrm{v})$. Hydrolyzed lipids were then extracted thrice with $n$-hexane/dichloromethane (DCM; 4:1, v/v), dried over $\mathrm{Na}_{2} \mathrm{SO}_{4}$, evaporated to dryness and resuspended in $n$-hexane/propan-2-ol (99:1, v/v) before being analyzed by high performance liquid chromatography-mass spectrometry following a procedure modified after Hopmans et al. (2000). It is noteworthy that the acid-hydrolysis of cells resulted in the degradation of all the unsaturated $\mathrm{C}_{30}$ (squalane), $\mathrm{C}_{35}$ and $\mathrm{C}_{40}$ (lycopane) isoprenoid derivatives (apolar lipids) for which a separate extraction procedure was considered (see below).

\section{Extraction of Total Lipids (TLE) and Separation of Apolar Lipids}

Typically, the TLE was obtained from half of the cell pellet using a slightly modified Bligh and Dyer method (B\&D; Bligh and Dyer, 1959). Cells were first resuspended in pure water (pre-extracted with DCM), transferred to a glass tube and $\mathrm{MeOH}$ and DCM were added to achieve a final ratio of 1:2:0.8 $\mathrm{DCM} / \mathrm{MeOH} /$ water (v/v/v). The suspension was sonicated $5 \mathrm{~min}$ with a probe and centrifuged at $4500 \mathrm{rpm}$ for $10 \mathrm{~min}$. The supernatant was collected and the extraction of the cells was repeated twice. The three respective supernatants were combined and the volume was adjusted to a final $\mathrm{DCM} / \mathrm{MeOH} /$ water ratio of 1:1:0.9 (v/v/v) allowing the separation of two phases. The lower organic phase was collected and the water phase was further extracted twice with DCM. The three respective organic phases were combined and concentrated by rotary evaporation to yield the TLE. Elemental sulfur $\left(\mathrm{S}_{0}\right)$ present in the TLE was removed with activated copper overnight at $4^{\circ} \mathrm{C}$. The TLE was then separated into an apolar and a polar lipid fraction by silica column chromatography using $n$-hexane/DCM (4:1, v/v, apolar lipids) and $\mathrm{DCM} / \mathrm{MeOH}$ (1:1, v/v, polar lipids), respectively. The apolar fraction was further separated into saturated and unsaturated compounds using a column of silica impregnated with silver nitrate $\left(\mathrm{SiO}_{2}, \mathrm{AgNO}_{3}, 20 \%\right.$, w/w). Elution with $n$ hexane and ethyl acetate yielded the saturated hydrocarbons and the total alkene fraction, respectively. Hydrogenation of half of the alkene fraction was performed under a hydrogen atmosphere in ethyl acetate containing a drop of acetic acid and $\mathrm{Pd} / \mathrm{CaCO}_{3}$ as catalyst.

\section{Tests of Lipid Extraction Efficiency in T. barophilus}

To assay the efficiency of the extraction procedures on the recovery of $T$. barophilus lipids, several commonly used procedures were tested. Three total lipid extractions were performed on independent cell pellets: (1) the classical B\&D extraction, (2) the trichloroacetic acid acidified B\&D extraction (TCA B\&D) proposed by Nishihara and Koga (1987) to increase lipid extraction efficiency from thermoacidophiles, and (3) extraction with DCM and $\mathrm{MeOH}$ (1:1, v:v; four times). Following the extraction step, TLE were further purified as described above to remove elemental sulfur. Lipid yields are expressed as percent of the dry weight of cells $(\mathrm{cdw})$. The ratio of di- to tetraether $(\mathrm{D} / \mathrm{T})$ was estimated by liquid chromatography-mass spectrometry (LC-MS; see below) after acid hydrolysis of the extracts and compared to the ratio obtained by direct hydrolysis of cell pellets under acidic or basic conditions.

\section{GC-MS and LC-MS Analyses of Lipid Extracts}

Apolar lipids were analyzed by gas chromatography-mass spectrometry (GC-MS) using a MD800 Voyager spectrometer operating at $70 \mathrm{eV}$ and interfaced to an HP6890 gas chromato- 

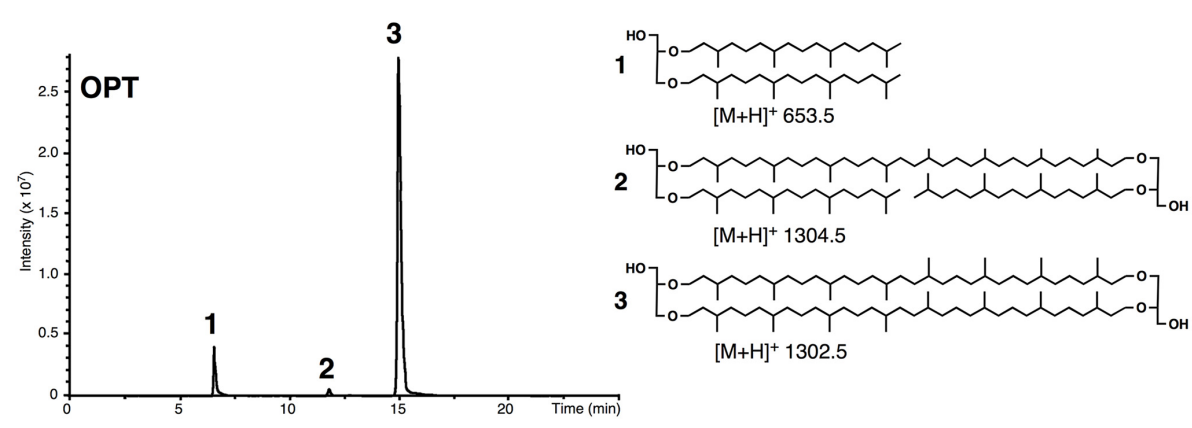

$[\mathrm{M}+\mathrm{H}]^{+} 1304.5$

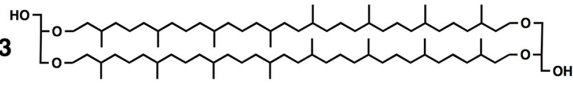

$[\mathrm{M}+\mathrm{H}]^{+} 1302.5$
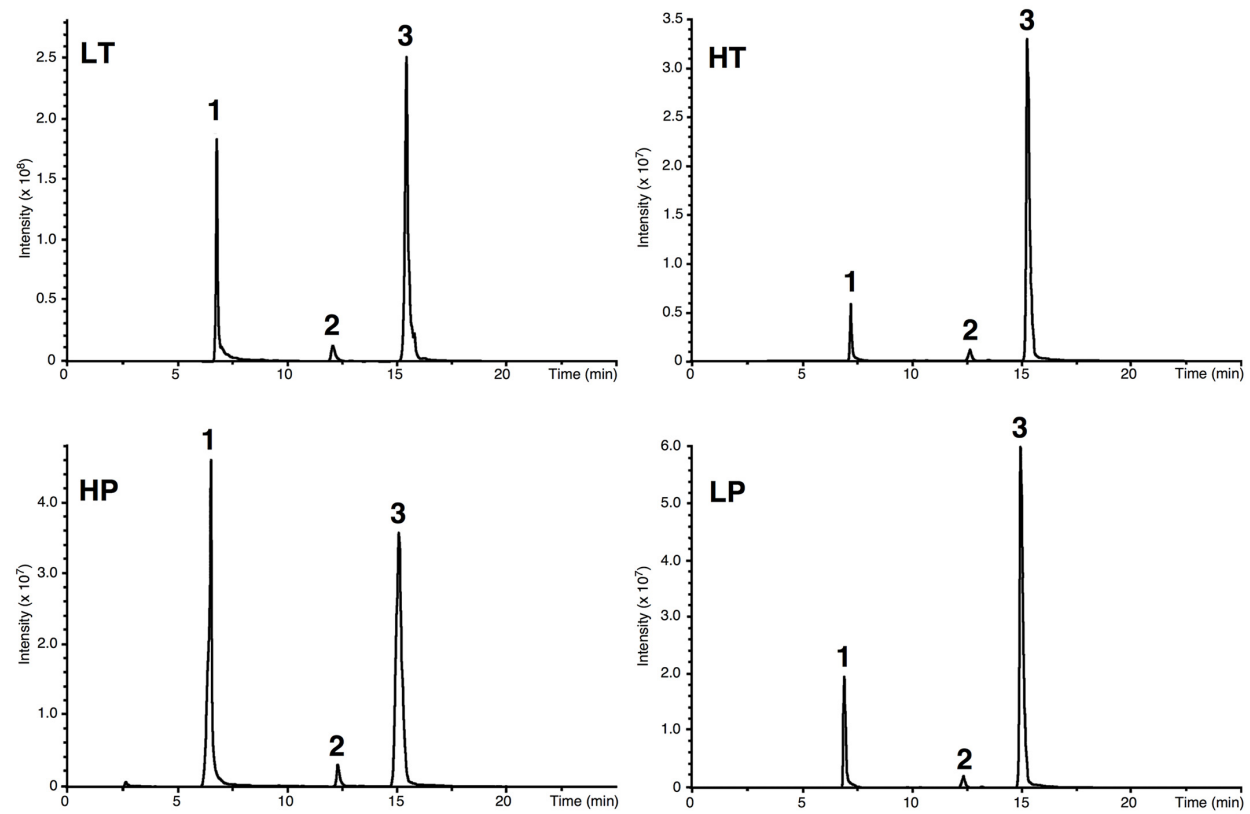

FIGURE 2 | Example of high performance liquid chromatography-mass spectrometry (HPLC-MS) chromatograms of the lipid extract of acid-hydrolyzed cells of $\mathbf{T}$. barophilus. Cells were grown at optimal pressure and temperature $\left(\mathrm{OPT}, 40 \mathrm{MPa}, 85^{\circ} \mathrm{C}\right)$, low temperature (LT, $\left.40 \mathrm{MPa}, 75^{\circ} \mathrm{C}\right)$, high pressure ( $\left.\mathrm{HP}, 70 \mathrm{MPa}, 85^{\circ} \mathrm{C}\right)$, low pressure (LP, $\left.0.1 \mathrm{MPa}, 85^{\circ} \mathrm{C}\right)$, or high temperature $\left(\mathrm{HT}, 40 \mathrm{MPa}, 90^{\circ} \mathrm{C}\right)$. (1) Diphytanyl glycerol diether (archaeol); (2) glycerol trialkyl glycerol tetraether (GTGT); (3) glycerol dibiphytanyl glycerol tetraether (GDGT-0).

graph equipped with an on-column injector and a DB-5MS column $(30 \mathrm{~m} \times 0.25 \mathrm{~mm} \times 0.25 \mu \mathrm{m})$. The oven temperature was programmed from $60^{\circ} \mathrm{C}(1 \mathrm{~min})$ to $130^{\circ} \mathrm{C}$ at $20^{\circ} \mathrm{C} \mathrm{min} \mathrm{m}^{-1}$, then to $300^{\circ} \mathrm{C}$ at $4^{\circ} \mathrm{C} \min ^{-1}(30 \mathrm{~min})$. Helium was used as the carrier gas at constant flow $\left(1 \mathrm{ml} \mathrm{min}^{-1}\right)$. Quantitation of unsaturated hydrocarbons was performed using squalane as external standard.

Hydrolyzed core lipids of T. barophilus were analyzed by LCMS using an HP 1100 series LC-MS instrument equipped with an auto-injector and a Chemstation chromatography manager software. The analytical conditions were modified after Hopmans et al. (2000). Separations were achieved on a Prevail Cyano 3 microns column $(150 \mathrm{~mm} \times 2.1 \mathrm{~mm}$; Grace Davison Discovery Sciences) maintained at $30^{\circ} \mathrm{C}$. Injection volumes varied from 5 to $10 \mu \mathrm{l}$. Archaeol and GDGT-0 were eluted in the same run with a flow rate of $0.8 \mathrm{ml} \mathrm{min}^{-1}$, using a linear gradient from $0.1 \% \mathrm{~A}$ and $99.9 \% \mathrm{~B}$ to $1.3 \% \mathrm{~A}$ in $30 \mathrm{~min}(\mathrm{~A}=$ propan- 2 -ol, $\mathrm{B}=n$-hexane), followed by a gradient to $10 \% \mathrm{~A}$ in $5 \mathrm{~min}$ (10 $\mathrm{min}$ isocratic), and back to $0.1 \% \mathrm{~A}$ in $5 \mathrm{~min}$. Detection was achieved using an
Esquire $3000+$ ion trap mass spectrometer with an atmospheric pressure positive ion chemical ionization source (APCI-MS). Conditions for MS analyses were: nebulizer pressure $50 \mathrm{psi}, \mathrm{APCI}$ temperature $350^{\circ} \mathrm{C}$, drying temperature $300^{\circ} \mathrm{C}$, drying gas $\left(\mathrm{N}_{2}\right)$ flow five $1 \mathrm{~min}^{-1}$ and temperature $300^{\circ} \mathrm{C}$, capillary voltage $-2 \mathrm{kV}$, corona 4 microamperes, scan range $m / z$ 600-1400. Mass spectra were systematically background-corrected.

\section{RESULTS}

\section{Lipid Composition of T. barophilus Grown under Optimal Conditions}

Acid-hydrolyzed core lipids of T. barophilus grown under optimal growth conditions (OPT) were analyzed by HPLC-APCI-MS. The major core lipids identified were GDGT-0 $\left([\mathrm{M}+\mathrm{H}]^{+} 1302.5\right.$; compound 3, Figure 2) and archaeol $\left([\mathrm{M}+\mathrm{H}]^{+}\right.$653.5; compound 1, Figure 2). A third core lipid present in trace amounts showed a protonated $[\mathrm{M}+\mathrm{H}]^{+}$ion at $m / z \quad 1304.5$ and was identified 
as a glycerol-trialkyl-glycerol-tetraether (GTGT; compound 2, Figure 2). The latter compound, which contains one biphytanyl and two phytanyl chains, has been formerly proposed to be an intermediate of GDGT-0 biosynthesis (Schouten et al., 2000; Pitcher et al., 2011), although this has been recently subject to debate (Villanueva et al., 2014). H-shaped GDGT0 derivatives previously reported in several members of the Thermococcales (Sugai et al., 2004), GDGT with 1-4 cyclopentane ring(s) observed in some thermoacidophilic Archaea and sulfurdependent thermophiles (De Rosa et al., 1980b), and macrocyclic archaeol reported in two species of Methanococcus (Comita et al., 1984; Trincone et al., 1992), were not detected in T. barophilus strain MP. It is noteworthy that the response factors in MS of archaeol and GDGT-0 are not known but that they likely differ due to the higher number of protonable sites present in GDGT-0 compared to archaeol. Thus, the variations of the archaeol/GDGT-0 (D/T) ratio observed between growth conditions (Figure 2) indicate qualitative rather than quantitative changes between both classes of core lipids. Nonetheless, considering exclusively the two predominant compounds (i.e., archaeol and GDGT-0) present in the HPLC chromatogram, the area of the peak corresponding to GDGT-0 represented $84 \%$ of the ether lipids vs. $16 \%$ for archaeol.

Apolar lipids of T. barophilus grown under optimal conditions were detected only in the non-hydrolyzed TLE since they were destroyed upon acid hydrolysis. GC-MS analysis of the alkene fraction showed the presence of a main group of unsaturated hydrocarbons which were identified, based on their mass spectra, as $\mathrm{C}_{40}$ isoprenoid alkenes with one up to six double bonds. Two minor groups of $\mathrm{C}_{30}$ and $\mathrm{C}_{35}$ isoprenoid alkenes with 1-6 double bonds were also detected in trace amounts (Figure 3A). Catalytic hydrogenation of the apolar fraction confirmed that each group of alkenes share respectively the same $C_{40}, C_{35}$, and $\mathrm{C}_{30}$ hydrocarbon skeleton, which could be identified based on their characteristic mass spectral fragmentations as irregular isoprenoids (Figures 3B,C), namely lycopane $(2,6,10,14$, 19,23,27,31-octamethyldotriacontane), 2,6,10,14,19,23,27-heptamethyloctacosane and squalane (2,6,10,15,19,23-hexamethyltetracosane), respectively. $\mathrm{C}_{35}$ and $\mathrm{C}_{30}$ isoprenoids, present in low abundance in comparison to the $\mathrm{C}_{40}$ alkenes, were not considered further in this study. Unsaturated lycopanederivatives with three and four double bonds were the major isoprenoid hydrocarbons present in T. barophilus (Table 1; Figure $3 \mathbf{A}$ ). Due to the high number of double bonds in these $\mathrm{C}_{40}$ compounds and the low amounts of these compounds per cell, the exact position and the stereochemistry of the double bonds could not be determined. The relative proportion of the lycopene derivatives was estimated to represent ca. 1-2\% of total lipids of T. barophilus under optimal growth conditions.

\section{Influence of Pressure and Temperature on the Lipid Composition of T. barophilus}

The relative proportions of archaeol and GDGT-0 were determined and compared as a function of growth pressure and temperature, using suboptimal and supraoptimal conditions of pressure $(0.1$ and $70 \mathrm{MPa})$ or temperature $\left(75\right.$ and $\left.90^{\circ} \mathrm{C}\right)$, which have been shown previously to generate the same level of stress in cells of T. barophilus (Marteinsson et al., 1999). GTGT (compound 2, Figure 2) was observed only in trace amounts under all conditions tested. The $\mathrm{D} / \mathrm{T}$ ratio significantly varied as a function of growth temperature or pressure (Table 2). It increased from $8 / 92$ at HT to $45 / 55$ at LT, which corresponds to a ca. 10 -fold increase. The $\mathrm{D} / \mathrm{T}$ ratio under LP conditions slightly decreased in comparison to optimal conditions from $12 / 88$ to $16 / 84$ respectively, whereas it was much higher under $\mathrm{HP}$ conditions reaching 37/63, corresponding to a ca. sevenfold increase in comparison to OPT conditions.

In addition to variations in the relative proportions of the two major core lipids, the degree of unsaturation of lycopane derivatives synthesized by $T$. barophilus was also observed to vary according to conditions of pressure or temperature (Table 1; Figure 4). The average number of double bonds in unsaturated lycopane derivatives increased from 2.9 to 3.7 when the growth pressure was increased from 40 to $70 \mathrm{MPa}$, and decreased to 2.5 at atmospheric pressure. The effect of temperature mirrored that of pressure, with the average number of unsaturation in lycopane derivatives increasing to 3.8 at low temperature $\left(80^{\circ} \mathrm{C}\right)$, and decreasing to 2.2 at high temperature $\left(90^{\circ} \mathrm{C}\right.$; Table 1; Figure 4).

\section{Polar Lipid Extraction Efficiency in $T$. barophilus}

The previously reported absence of tetraether lipids in T. barophilus (Marteinsson et al., 1999) prompted us to evaluate the lipid extraction efficiency of different extraction protocols on the archaeal lipids from this species. To address this question, we compared the yield and composition of lipids extracted from T. barophilus (cells grown under optimal conditions) using three different procedures of extraction with solvents $(\mathrm{B} \& \mathrm{D}$, TCA $\mathrm{B} \& \mathrm{D}$, and $\mathrm{DCM} / \mathrm{MeOH})$ and direct acid-hydrolysis (Supplementary Figure S1). T. barophilus cells appeared extremely resistant to solvent extraction as evidenced by the poor yields of lipids obtained using the standard or acidified (TCA) B\&D procedures (Table 3 and Supplementary Figure S2). A better yield of TLE, i.e., 3.7\% cdw, was obtained with a monophasic extraction using a mixture of $\mathrm{DCM} / \mathrm{MeOH}$ $(2: 1, \mathrm{v} / \mathrm{v})$. This yield was still lower than yields reported for Thermococcales in the literature, which range between 5 and 10\% cdw (Langworthy, 1982). In fact, residual lipids were detected in significant amounts after acid hydrolysis of the residue from $B \& D$ pre-extracted cells, confirming incomplete lipid extraction using sonication (results not shown). Direct acid or base hydrolysis of the cell pellets yielded 5.0 and $1.4 \%$ of lipids cdw, respectively (Table 3). The yield obtained for the acid hydrolysis (5\% cdw) is in good agreement with the highest values reported in the literature $(10 \% \mathrm{cdw})$, considering acid hydrolized lipids lack the polar headgroup moieties and are therefore ca. twice lighter than the intact polar lipids obtained by the B\&D procedure. The absence of the polar headgroup results in the formation of relatively low-polar core lipids, the latter being more easily solvent-extractable, and can explain the higher yield obtained in the case of the acid hydrolysis procedure. In addition to yields, lipid extraction procedures also affected core lipid compositions. For example, the $\mathrm{B} \& \mathrm{D}$ and $\mathrm{AH}$ procedures yielded almost the same amount of archaeol (data not shown). However, archaeol 


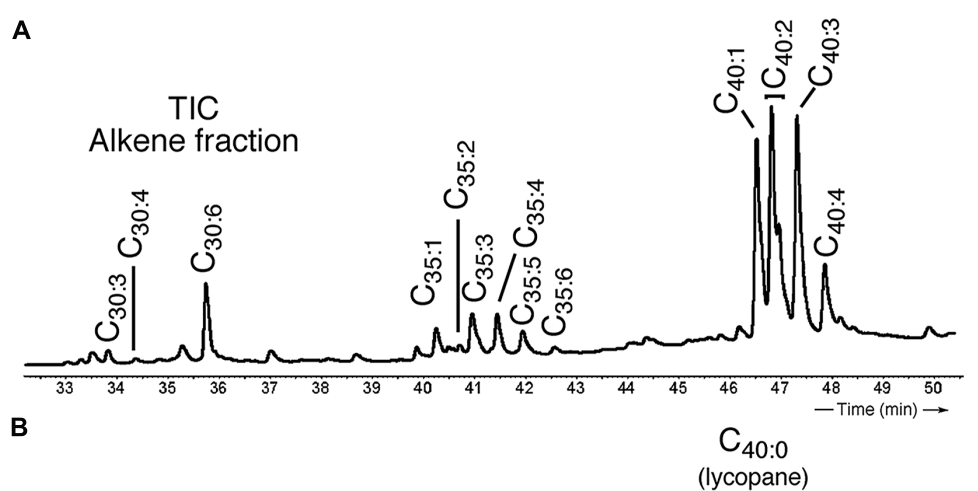

TIC

Hydrogenated alkene fraction
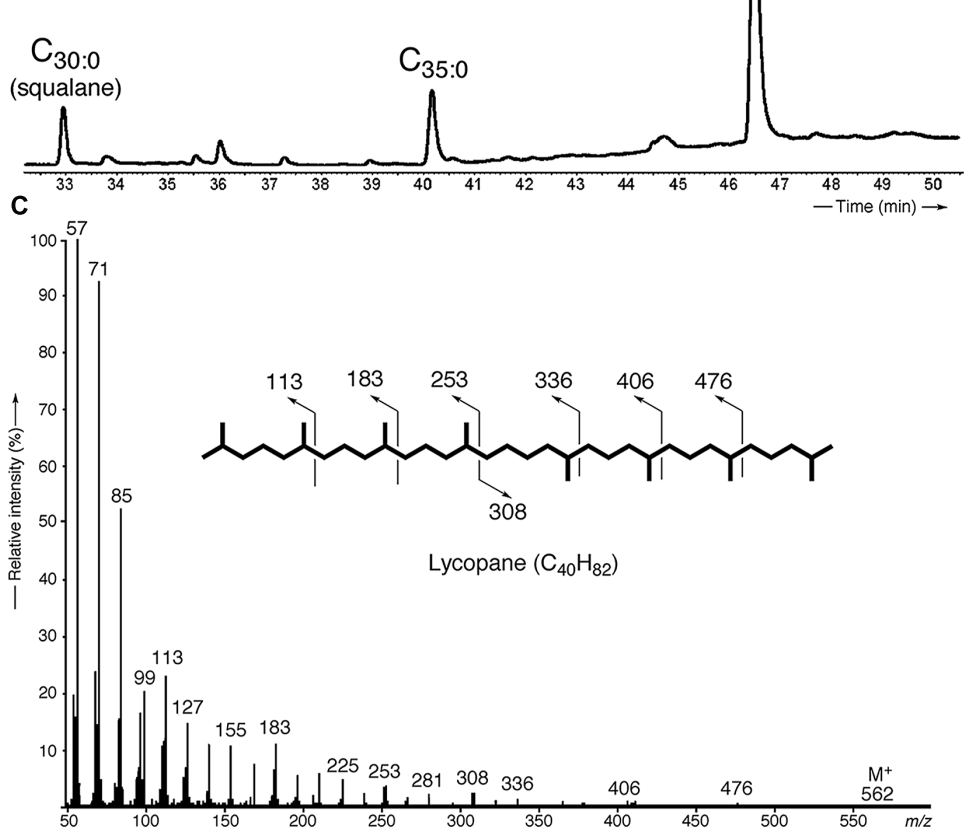

FIGURE 3 | Identification and characterization of polyunsaturated irregular isoprenoids in T. barophilus. (A) Partial gas chromatogram [total ion current (TIC)] showing the distribution of the polyunsaturated isoprenoids $\mathrm{C}_{30}$ (squalane), $\mathrm{C}_{35}$ and $\mathrm{C}_{40}$ (lycopane) derivatives; (B) Partial gas chromatogram (TIC) of a hydrogenated apolar lipid fraction; (C) Mass spectrum of lycopane following complete catalytic hydrogenation of the $\mathrm{C}_{40}$ lycopene derivatives.

TABLE 1 | Proportions and average number of double bonds of individual unsaturated lycopane derivatives biosynthesized by Thermococcus barophilus grown under different conditions of temperature and pressure.

\begin{tabular}{|c|c|c|c|c|c|c|c|}
\hline \multirow{2}{*}{$\begin{array}{l}\text { Culture } \\
\text { conditions }\end{array}$} & \multicolumn{6}{|c|}{ Relative proportions of $\mathrm{C}_{40}$ lycopane derivatives (\%) } & \multirow{2}{*}{$\begin{array}{c}\text { Average number of } \\
\text { unsaturations }\end{array}$} \\
\hline & $C_{40: 1}$ & $\mathrm{C}_{40: 2}$ & $C_{40: 3}$ & $\mathrm{C}_{40: 4}$ & $\mathrm{C}_{40: 5}$ & $\mathrm{C}_{40: 6}$ & \\
\hline HT & 28.8 & 34.5 & 26.2 & 10.5 & ND & ND & 2.2 \\
\hline LP & 16.0 & 39.5 & 27.4 & 17.1 & ND & ND & 2.5 \\
\hline OPT & 10.3 & 21.5 & 37.4 & 30.8 & $\operatorname{Tr}$ & ND & 2.9 \\
\hline $\mathrm{LT}$ & ND & 7.3 & 27.2 & 55.1 & 8.5 & 1.9 & 3.8 \\
\hline $\mathrm{HP}$ & ND & 10.5 & 28.6 & 45.9 & 11.2 & 3.8 & 3.7 \\
\hline
\end{tabular}

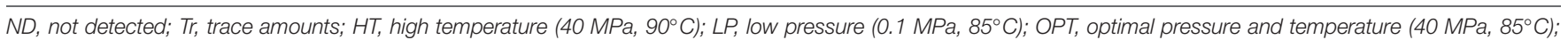
$\mathrm{HP}$, high pressure $\left(70 \mathrm{MPa}, 85^{\circ} \mathrm{C}\right)$; $L \mathrm{~T}$, low temperature $\left(40 \mathrm{MPa}, 80^{\circ} \mathrm{C}\right)$. 
TABLE 2 | D/T ratio of core lipids in $T$. barophilus as a function of pressure and temperature.

\begin{tabular}{lc}
\hline & D/T \\
\hline LT & $45 / 55 \pm 0.09$ \\
HP & $37 / 63 \pm 0.14$ \\
OPT & $16 / 84 \pm 0.04$ \\
LP & $12 / 88 \pm 0.03$ \\
HT & $8 / 92 \pm 0.02$ \\
\hline
\end{tabular}

Note that the relative proportions of archaeol and GDGT-0 have been determined by integration of the $[\mathrm{M}+\mathrm{H}]^{+}$peaks on the HPLC chromatograms using arbitrarily a 1:1 response factor for both compounds. The values are averages from at least three independent biological replicate experiments.

represented ca. $90 \%$ of the total core lipids extracted by the B\&D method compared to $16 \%$ with the direct hydrolysis of cell pellet method (Table 3). Acidification of the extraction solvent using TCA, which has been recommended for the extraction of lipids of hyperthermophilic acidophiles by Nishihara and Koga (1987), neither increased the extraction yield of lipids from $T$. barophilus nor corrected the core lipid composition bias (Table 3). The basic hydrolysis of membrane lipids yielded poor results, both in terms of yield (1.4\% cdw) and quality, e.g., altered D/T ratio (Table 3 ).

\section{DISCUSSION}

\section{GDGT-0 and Archaeol as Major Core Lipids of $T$. barophilus}

We investigated the membrane lipid composition and modification in response to variations in $\mathrm{P}$ and $\mathrm{T}$ in the piezo-hyperthermophilic archaeon $T$. barophilus strain MP, a strain capable of growth up to $103^{\circ} \mathrm{C}$ and $80 \mathrm{MPa}$. Our results first establish that the tetraether lipid GDGT-0 is one of the two major core lipids in T. barophilus. Thus far, this species has been considered to synthesize only archaeol and not GDGT-0 (Marteinsson et al., 1999). Its abundance relative to archaeol varies according to varying environmental conditions, i.e., temperature and pressure. The high proportion of GDGT-0 among the ether lipids of $T$. barophilus is in good agreement with the ability of this strain to grow at temperatures close to or above $100^{\circ} \mathrm{C}$. Indeed, bipolar tetraether lipids, which harbor hydrophilic moieties at both ends and long hydrophobic central domains, are synthesized by all hyperthermophilic and almost all thermophilic Archaea, and have been proposed to constitute an adaptive trait for growth at high temperature. Tetraether-based monolayer membranes exhibit a very high thermal stability and extreme rigidity (Elferink et al., 1994; Dante et al., 1995) and, consequently, a low permeability to water and ions. This is also consistent with the reported core lipid compositions of other Thermococcales, which optimal growth temperatures are distributed between 75 and $103^{\circ} \mathrm{C}$ and which all synthesize significant proportions of tetraether lipids (Sugai et al., 2004). Thus far, the lack of bipolar lipids in Thermococcales has been reported only in membranes of Pyrococcus woesei (Lanzotti et al., 1989) and Thermococcus celer (De Rosa et al., 1987) in addition to T. barophilus (Marteinsson

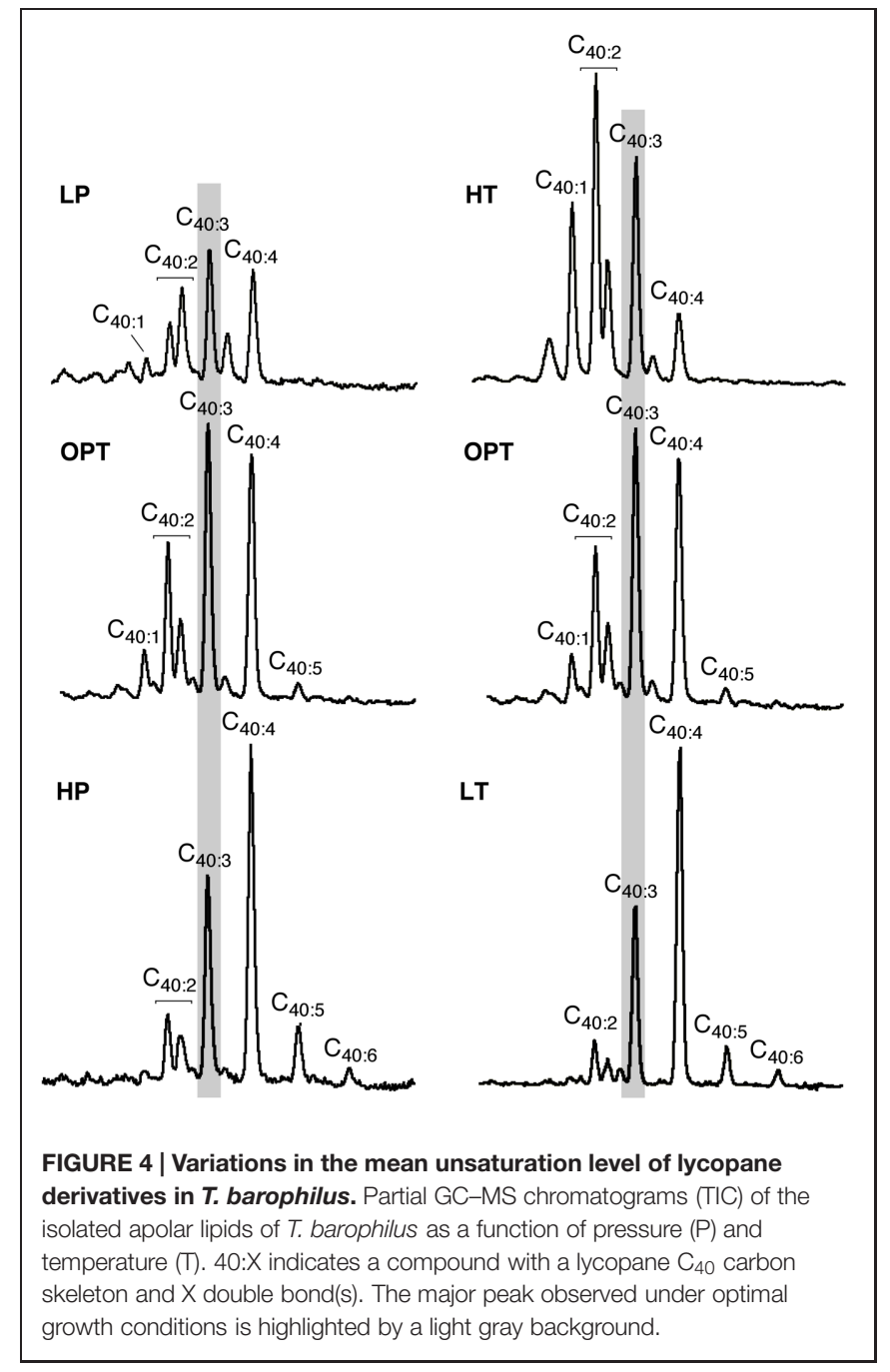

et al., 1999), which is rather in contradiction with the stability of the archaeol-based lipid bilayer required for growth at high temperature. Membrane lipid compositions of several Archaea have been shown to vary with the cell growth phase and the growth medium composition (Matsuno et al., 2009; Meador et al., 2014). These studies demonstrated a strong impact of the growth phase on the relative proportions of di- vs. tetraether lipids, but neither study reported the complete absence of one of these two lipid pools, suggesting that the lack of tetraethers in these species may stem from technical issues. Later analyses of $T$. celer and P. woese i indeed showed that GDGT-0 is a major lipid of these species (Sugai et al., 2004), which is consistent with the proposed role played by GDGT-0 in membrane stability of hyperthermophiles. Similar discrepancies in whole cell lipid compositions exist in the literature for other Thermococcales, such as T. kodakarensis (Sugai et al., 2004; Meador et al., 2014; Bauersachs et al., 2015). We hypothesized that these differences may stem from the distinct lipid extraction procedures applied in the different studies, e.g., direct hydrolysis of polar headgroups followed by core lipid extraction (this study and that of Sugai et al., 2004) or intact polar lipid extraction by B\&D followed by 
TABLE 3 | Extraction yields of total intact lipids and hydrolyzed polar lipids (core lipids) from mid exponential phase cells of $T$. barophilus grown under optimal conditions ( $3 \%$ salinity, $\left.85^{\circ} \mathrm{C}, 40 \mathrm{MPa}\right)$.

\begin{tabular}{|c|c|c|c|c|c|}
\hline & $\begin{array}{l}\text { Solvents used for } \\
\text { lipid extraction }\end{array}$ & $\begin{array}{l}\text { Type of lipids } \\
\text { extracted }\end{array}$ & $\%$ cdw & $\begin{array}{l}\text { Number of } \\
\text { replicates }\end{array}$ & $\mathrm{D} / \mathrm{T}$ \\
\hline$B \& D$ & $\begin{array}{l}\text { Biphasic } \\
\mathrm{MeOH} / \mathrm{DCM} / \mathrm{H}_{2} \mathrm{O} \\
(1: 1: 0.9, \mathrm{v} / \mathrm{v} / \mathrm{v})\end{array}$ & $\begin{array}{l}\text { Intact polar and } \\
\text { apolar lipids* }\end{array}$ & $1.2 \pm 0.5$ & $n=5$ & $90 / 10$ \\
\hline TCA & $\begin{array}{l}\text { Biphasic } \\
\text { MeOH/DCM/TCA 5\% } \\
(1: 1: 0.9, \mathrm{v} / \mathrm{v} / \mathrm{v})\end{array}$ & $\begin{array}{l}\text { Intact polar and } \\
\text { apolar lipids* }\end{array}$ & $0.8 \pm 0.3$ & $n=3$ & $98 / 2$ \\
\hline DCM/MeOH & $\begin{array}{l}\text { Monophasic } \\
\mathrm{DCM} / \mathrm{MeOH}(2: 1, \mathrm{v} / \mathrm{v})\end{array}$ & $\begin{array}{l}\text { Intact polar and } \\
\text { apolar lipids* }\end{array}$ & $3.7 \pm 1.3$ & $n=4$ & $60 / 40$ \\
\hline $\mathrm{AH}$ & $\begin{array}{l}\mathrm{HCl} / \mathrm{MeOH} \\
(10 \% \mathrm{HCl} 12 \mathrm{~N} \text { in } \\
\mathrm{MeOH})\end{array}$ & Core lipids & $5.0 \pm 0.5$ & $n=5$ & $16 / 84$ \\
\hline $\mathrm{BH}$ & $\begin{array}{l}1 \mathrm{~N} \mathrm{KOH} \text { in } \mathrm{MeOH} / \mathrm{H}_{2} \mathrm{O} \\
(1: 1, v / v)\end{array}$ & $\begin{array}{l}\text { Core lipids and } \\
\text { apolar lipids }\end{array}$ & $1.4 \pm 0.2$ & $n=2$ & $6 / 94$ \\
\hline
\end{tabular}

Yields are given as percent of cell dry weight (cdw).

B\&D, Bligh and Dyer; TCA, TCA acidified B\&D; DCM+MeOH; dichloromethane:methanol, 1:1, v/v; AH, acid hydrolysis; BH, base hydrolysis; DCM, dichloromethane; $\mathrm{MeOH}$, methanol; D/T, diether/tetraether ratio (archaeol/GDGT-0).

* Half of the lipid extract is further hydrolyzed $(\mathrm{HCl} / \mathrm{MeOH})$ prior to $\mathrm{LC}-\mathrm{MS}$ analysis of ether lipids.

polar headgroup hydrolysis. To test this hypothesis, we evaluated the ability of different lipid extraction protocols on T. barophilus cells (Supplementary Figure S2 and Table 3). Our results clearly show that intact polar tetraether lipids are very poorly extracted from $T$. barophilus cells with the $\mathrm{B} \& \mathrm{D}$ procedure, as indicated by the $\mathrm{D} / \mathrm{T}$ ratio of $90 / 10$ obtained upon hydrolysis of the lipid extract which shows that diethers are preferentially recovered over GDGT-0 (Table 3). The exact lipid extraction and lipid analysis procedures used in the original T. barophilus description is unknown since not reported by the authors. It is, however, likely that it followed the widely used B\&D or TCA approaches. In our hands, the use of the TCA extraction lead to the lowest yields $(0.8 \% \mathrm{cdw})$ and almost no tetraether were extracted $(\mathrm{D} / \mathrm{T}=98 / 2)$. These poor yields could explain why the original study did not report the presence of polar tetraether lipids in T. barophilus (Marteinsson et al., 1999). Consistent with these observations, acid hydrolysis of the residue of cells pre-extracted using the B\&D procedure yielded significant amounts of GDGT0 and of archaeol (data not shown). Noticeably, although the monophasic DCM/MeOH approach yielded the best results, none of the protocols tested appeared able to extract the totality of the polar lipids of T. barophilus. Altogether, these observations suggest that results of intact polar lipid compositions should be regarded with caution for certain archaeal species, and evaluated on a strain-to-strain basis using different extraction procedures.

\section{Evidence for Homeoviscous Adaptation in T. barophilus}

The modification of the $\mathrm{D} / \mathrm{T}$ ratio observed when $T$. barophilus was submitted to temperature variations is in good agreement with that previously reported for Archaea harboring mixed diphytanyl diether and dibiphytanyl tetraether lipids, such as T. kodakarensis (Sprott et al., 1991; Matsuno et al., 2009; Meador et al., 2014) or Archaeoglobus fulgidus (Sprott et al., 1991; Lai et al., 2008). A decrease of the $\mathrm{D} / \mathrm{T}$ ratio is expected to result in the stabilization of the membranes since it will form monolayers. In monolayer domains, the lipid packing is increased, which helps to regulate the flux of solutes and protons across the membranes. Conversely, an increase of this ratio is expected to increase membrane fluidity and permeability (Chong et al., 2012). Thus, regulation of the proportions of di- vs. tetraether lipids likely constitutes part of the homeoviscous response of Archaea to variations in temperature (Oger and Cario, 2013). We report here that $T$. barophilus is also capable of regulating the relative proportion of $\mathrm{di}$ - and tetraethers as a function of hydrostatic pressure. An increase from 54 to $64 \%$ of the relative proportion of archaeol in response to an increase of pressure from atmospheric to $50 \mathrm{MPa}$ has been previously observed in the piezophilic methanogen Methanocaldococcus jannaschii (Kaneshiro and Clark, 1995), which is the only example to date of homeoviscous adaptation of the archaeal membrane in response to variations of hydrostatic pressure. Since increasing hydrostatic pressure induces increased lipid compaction, the observed compositional variations can be interpreted in the framework of homeoviscous adaptation of the membrane to varying hydrostatic pressure. Interestingly, in addition to this modification of the ether lipid composition, our results show that the unsaturation level of the apolar lipids of T. barophilus increases with increasing pressure and decreasing temperature (Figure 4). The regulation of the unsaturation level of membrane lipids is a homeoviscous adaptation strategy frequently observed in psychrophilic bacteria (Wirsen et al., 1986; Yayanos, 1986). Such a strategy has been reported for the psychrophilic archaeon Methanococcoides burtonii which accumulates unsaturated archaeol derivatives in response to a lowering in temperature (Nichols et al., 2004). As far as we know, the present work is the first report of the regulation of the unsaturation level of apolar lipids in a thermophile. A similar modification of the degree of unsaturation of apolar lipids has 
A

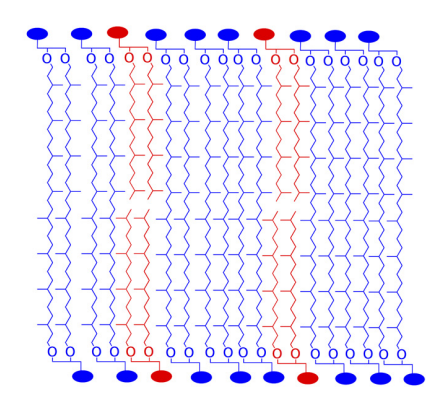

C

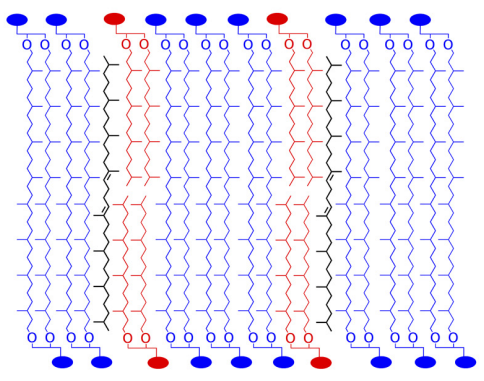

B

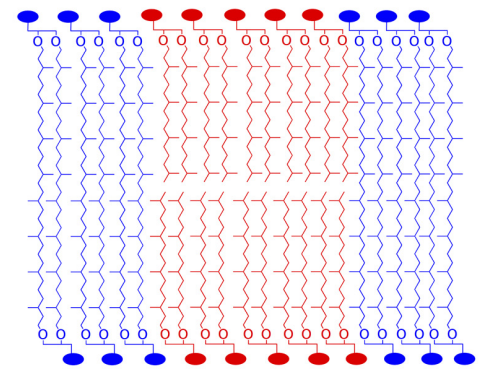

D

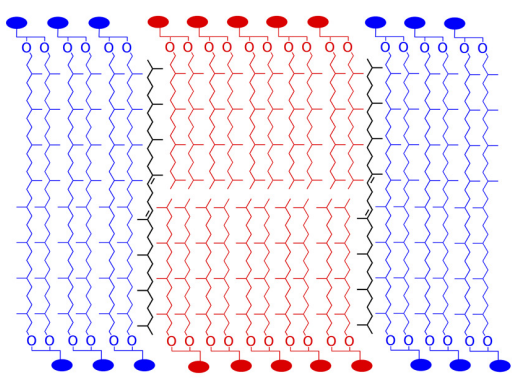

E

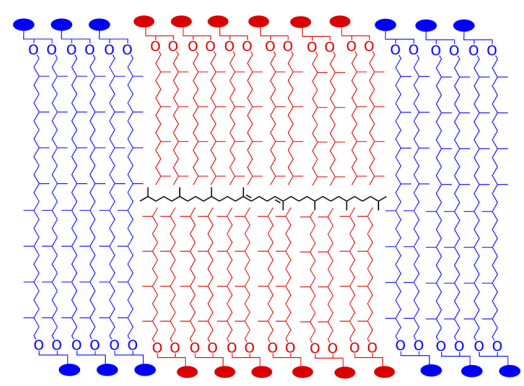

Polar head groups

FIGURE 5 | Stylized schematic representation of lipid organization in putative archaeal membrane models. Homogenous lipid mix of di- and tetraether lipids (A), coexistence of monolayer and bilayer domains (B). As proposed by Lanyi et al. (1974) or Gilmore et al. (2013), lycopane-derivatives in the hydrophobic region of the membrane in parallel to the isoprenoid chains in a homogenous (C) or bilayer domain-containing (D) membrane. In contrast, lycopane-derivatives could be inserted in the hydrophobic midplane of bilayer microdomains in parallel to the surface of the membrane (E), as also suggested by Haines (2001) for squalane in membranes of halophiles.

been observed for polyunsaturated squalane derivatives produced by methanogens and halophiles as a function of growth stage and aeration (Langworthy et al., 1972, 1974; Tornabene, 1978). The regulation of the unsaturation level of polyunsaturated lycopane derivatives in $T$. barophilus cells as a function of pressure and temperature conditions could indicate a possible role in homeoviscous adaptation, in addition to the regulation of the ratio of di- vs. tetraether core lipids.

\section{Are Apolar Lipids of T. barophilus Membrane Lipids?}

The cellular function of apolar lipids in Archaea, Eukarya, and Bacteria remains unclear. Cellular lipids can fulfill three general functions. First, they are used to form the matrix of cellular membranes. Second, because of their reduced state, they can serve as efficient storage of caloric reserves and stocks of fatty acid components that are needed for membrane biogenesis. Third, lipids can act as first and second messengers in signal transduction and molecular recognition processes (Fernandis and Wenk, 2007; van Meer et al., 2008). The latter function can be ruled out, since there is no evidence of lipid signaling in Bacteria or Archaea. Furthermore, we show that apolar lipids are accumulated in very low concentrations in T. barophilus cells, ca. 1-2\% of total lipids, which does not support a major role for these lipids as energy storage. It is also unlikely that apolar isoprenoid hydrocarbons of $T$. barophilus could serve as building blocks for archaeal polar lipid biosynthesis or could be derived from polar lipid degradation, since lycopane-type isoprenoid chains are derived from a tail-to-tail condensation of two phytanyl isoprenoid chains, as opposed 
to the head-to-head condensation of the biphytane isoprenoid chains observed in GDGTs from archaea. The regulation of the level of unsaturation of the lycopane derivatives as a function of pressure and temperature in $T$. barophilus may support a role of these apolar lipids in homeoviscous adaptation and, thus, their presence in membranes. In addition to this species and Thermococcus litoralis (Lattuati et al., 1998), irregular polyunsaturated isoprenoid lipids have been observed in methanogens, halophiles and alkaliphiles, but have never been detected in thermoacidophiles (Langworthy, 1982). Experiments performed on archaeal lipids in the presence or absence of apolar lipids revealed that the domain structure in monolayered membranes is strongly influenced by the apolar components (Gilmore et al., 2013). These experiments demonstrated that in these archaeal membrane analogs, squalene plays a function similar to that of cholesterol in eukaryotic membranes, helping to orient the lipid tails away from the interface. This allows the lipid tails to pack more closely together, lowering the average area per molecule. The enhanced order leads to the formation of domains in the membrane in the presence of squalene (Gilmore et al., 2013), and to an increased impermeability of the membrane (Lanyi et al., 1974). In the absence of a midplane interface, squalane derivatives could insert within the hydrophobic domain in parallel to the isoprenoid chains. The location of squalene in bilayered membranes remains a subject of debate. Indeed, Haines (2001) and Hauß et al. (2002) have demonstrated that squalane molecules could sit at the midplane of the lipid bilayers, in parallel to the surface of the membrane. By crowding the inner space of the bilayer, the presence of isoprenoid hydrocarbons in the midplane would explain two specific properties of the halophilic membrane: first the decreased proton and water permeability and second the increased membrane rigidity (Haines, 2001). This proposed ultrastructure is yet to be confirmed in membranes of extreme halophiles. In $T$. barophilus, membrane lipids consist of a majority of tetraether and diether lipids and ca. 1-2\% of apolar lipids, which raises questions about the spatial arrangements of these molecules in the membrane. The membrane could be composed of a monolayer matrix constituted by a homogenous mix of tetraether and diether lipids (Figure 5A). Alternatively, the membrane could be constituted of coexisting domains of bilayers and monolayers (Figure 5B). Polyunsaturated lycopanederivatives could insert similarly to cholesterol in eukaryotic membranes as proposed by Lanyi et al. (1974) and Gilmore et al. (2013; Figures 5C,D). Alternatively, these apolar lipids may insert in the midplane of the bilayer domains formed by diether lipids, parallel to the plane of the membrane as proposed for extreme halophiles by Haines (2001) and Hauß et al. (2002; Figure 5E). The presence of a significant proportion of archaeol in $T$. barophilus makes the existence of such bilayer membrane domains plausible. Whether models $\mathrm{C}, \mathrm{D}$, or $\mathrm{E}$ are valid remains to be addressed. As mentioned above, membrane structures based on models $\mathrm{C}$ or $\mathrm{D}$ would yield increased membrane rigidity and impermeability under high temperature. In contrast, benefits associated with model E would combine the increased membrane fluidity of the archaeol-based membrane and the increased rigidity and reduced permeability brought by the unsaturated lycopane derivatives present in the midplane of the bilayer. Thus, altering the degree of unsaturation of lycopane derivatives and promoting a bilayer-type membrane could strongly modify the melting transition temperatures and lead to more fluid membrane domains under low temperature or high pressure conditions (Smeller, 2002), and represent a possible adaptation strategy in T. barophilus.

\section{CONCLUSION}

The current study sheds light on homeoviscous adaptation of the membrane lipid composition of one of the major groups of archaeal hyperthermophiles from deep-sea hydrothermal vents. In contrast to previous reports, we show that the tetraether lipid GDGT-0 is among the major core lipids in the piezophilic hyperthermophile T. barophilus. We demonstrate that membrane adaptation in hyperthermophilic HHP-adapted Archaea involves the same mechanistic response (e.g., regulation of the relative proportions of di- vs. tetraether lipids) as that previously observed for other environmental parameters such as $\mathrm{pH}$ and temperature. We further demonstrate that the structures of non-polar isoprenoid lipids synthesized by this archaeon are also affected by temperature or hydrostatic pressure variations, raising numerous questions regarding the role of these apolar lipids in the structure and adaptation of the membrane of Archaea composed of di- and tetraether lipids. Apolar lipids drastically modify the physical properties of archaeal membrane analogs, but the way they interact with polar lipids remains to be investigated. Amongst possible membrane models that can be proposed for Archaea synthesizing both di- and tetraether lipids, some suggest the existence of micro domains within the membrane into which apolar lipids could be inserted, leading to structures similar to the lipid rafts of eukaryotes. Since membrane properties differ drastically in lipid rafts, the latter are essential for several specific cellular functions. The existence of lipid rafts could help explaining how Archaea with very close membrane lipid compositions cope with very different external environmental conditions. Further studies are required to confirm or infirm the existence of lipid rafts in archaeal membranes.

\section{FUNDING}

AC was supported by a Ph.D. grant from the French Ministry of Research and Technology. This work was supported by grant ANR Living Deep (ANR-2010-BLAN-1725) from the Agence Nationale de la Recherche and the PEPS ExoMod program of the CNRS to PO.

\section{SUPPLEMENTARY MATERIAL}

The Supplementary Material for this article can be found online at: http://journal.frontiersin.org/article/10.3389/fmicb. 2015.01152 


\section{REFERENCES}

Bauersachs, T., Weidenbach, K., Schmitz, R. A., and Schwark, L. (2015). Distribution of glycerol ether lipids in halophilic, methanogenic and hyperthermophilic Archaea. Org. Geochem. 8, 101-108. doi: 10.1016/j.orggeochem.2015.03.009

Bligh, E. G., and Dyer, W. J. (1959). A rapid method of total lipid extraction and purification. Can. J. Biochem. Physiol. 37, 911-917. doi: 10.1139/o59-099

Boyd, E. S., Pearson, A., Pi, Y., Li, W.-J., Zhang, Y. G., He, L., et al. (2011). Temperature and $\mathrm{pH}$ controls on glycerol dibiphytanyl glycerol tetraether lipid composition in the hyperthermophilic crenarchaeon Acidilobus sulfurireducens. Extremophiles 15, 59-65. doi: 10.1007/s00792-010-0339-y

Chong, P. L. G., Ayesa, U., Daswani, V., and Hur, E. (2012). On physical properties of tetraether lipid membranes: effects of cyclopentane rings. Archaea 2012:11. doi: 10.1155/2012/138439

Comita, P. B., Gagosian, R. B., Pang, H., and Costello, C. E. (1984). Structural elucidation of a unique macrocyclic membrane lipid from a new extremophilic, deep-sea hydrothermal vent archaebacterium, Methanococcus jannaschii. J. Biol. Chem. 259, 5234-5241.

Dante, S., De Rosa, M., Maccioni, E., Morana, A., Nicolini, C., Rustichelli, F., et al. (1995). Thermal, stability of bipolar lipid Langmuir Blodgett films by X-Ray diffraction. Mol. Cryst. Liq. Cryst. 262, 191-207. doi: $10.1080 / 10587259508033525$

De Rosa, M., Esposito, E., Gambacorta, A., Nicolaus, B., and Bu’lock, J. D. (1980a). Effects of temperature on ether lipid composition of Caldariella acidophila. Phytochemistry 19, 827-831. doi: 10.1016/0031-9422(80)85120-X

De Rosa, M., Gambacorta, A., Nicolaus, B., and Bu'lock, J. D. (1980b). Complex lipids of Caldariella acidophila, a thermoacidophile archaebacterium. Phytochemistry 19, 821-825. doi: 10.1016/0031-9422(80)85119-3

De Rosa, M., and Gambacorta, A. (1988). The lipids of archaebacteria. Prog. Lipid Res. 27, 153-175. doi: 10.1016/0163-7827(88)90011-12

De Rosa, M., Gambacorta, A., Trincone, A., Basso, A., Zillig, W., and Holz, I. (1987). Lipids of Thermococcus celer, a sulfur-reducing Archaebacterium Structure and biosynthesis. Syst. Appl. Microbiol. 9, 1-5. doi: 10.1016/S07232020(87)80046-2

Elferink, M. G. L., Dewit, J. G., Driessen, A. J. M., and Konings, W. N. (1994). Stability and proton permeability of liposomes composed of archaeal tetraether lipids. Biochim. Biophys. Acta 1193, 247-254. doi: 10.1016/00052736(94)90160-0

Fernandis, A. Z., and Wenk, M. R. (2007). Membrane lipids as signaling molecules. Curr. Opin. Lipidol. 18, 121-128. doi: 10.1097/MOL.0b013e328082e4d5

Flores, G. E., Campbell, J. H., Kirshtein, J. D., Meneghin, J., Podar, M., Steinberg, J. I., et al. (2011). Microbial community structure of hydrothermal deposits from geochemically different vent fields along the Mid-Atlantic Ridge. Environ. Microbiol. 13, 2158-2171. doi: 10.1111/j.1462-2920.2011.0 2463. $\mathrm{x}$

Flores, G. E., Shakya, M., Meneghin, J., Yang, Z. K., Seewald, J. S., Wheat, C. G., et al. (2012). Inter-field variability in the microbial communities of hydrothermal vent deposits from a back-arc basin. Geobiology 10, 333-346. doi: 10.1111/j.1472-4669.2012.00325.x

Gabriel, J., and Chong, P. L. G. (2000). Molecular modeling of archaebacterial bipolar tetraether lipid membranes. Chem. Phys. Lipids 105, 193-200. doi: 10.1016/S0009-3084(00)00126-2

Gibson, J. A. E., Miller, M. R., Davies, N. W., Neill, G. P., Nichols, D. S., and Volkman, J. K. (2005). Unsaturated diether lipids in the psychrotrophic archaeon Halorubrum lacusprofundi. Syst. Appl. Microbiol. 28, 19-26. doi: 10.1016/j.syapm.2004.09.004

Gilmore, S. F., Yao, A. I., Tietel, Z., Kind, T., Facciotti, M. T., and Parikh, A. N. (2013). Role of squalene in the organization of monolayers derived from lipid extracts of Halobacterium salinarum. Langmuir 29, 7922-7930. doi: 10.1021/la401412t

Gliozzi, A., Paoli, G., De Rosa, M., and Gambacorta, A. (1983). Effect of isoprenoid cyclization on the transition temperature of lipids in thermophilic archaebacteria. Biochim. Biophys. Acta-Biomembranes 735, 234-242. doi: 10.1016/0005-2736(83)90298-5

Hafenbradl, D., Keller, M., and Stetter, K. O. (1996). Lipid analysis of Methanopyrus kandleri. FEMS Microbiol. Lett. 136, 199-202. doi: 10.1111/j.1574-6968.1996.tb08049.x
Haines, T. H. (2001). Do sterols reduce proton and sodium leaks through lipid bilayers? Prog. Lipid Res. 40, 299-324. doi: 10.1016/S0163-7827(01)0 0009-1

Hanford, M. J., and Peeples, T. L. (2002). Archaeal tetraether lipids. Appl. Biochem. Biotechnol. 97, 45-62. doi: 10.1385/ABAB:97:1:45

Hauß, T., Dante, S., Dencher, N. A., and Haines, T. H. (2002). Squalane is in the midplane of the lipid bilayer: implications for its function as a proton permeability barrier. Biochim. Biophys. Acta 1556, 149-154. doi: 10.1016/S00052728(02)00346-8

Hazel, J. R. (1995). Thermal adaptation in biological membranes - is homeoviscous adaptation the explanation? Ann. Rev. Physiol. 57, 19-42. doi: 10.1146/annurev.ph.57.030195.000315

Hopmans, E. C., Schouten, S., Pancost, R. D., Van Der Meer, M. T. J., and Damsté, J. S. S. (2000). Analysis of intact tetraether lipids in archaeal cell material and sediments by high performance liquid chromatography/atmospheric pressure chemical ionization mass spectrometry. Rapid Commun. Mass Spectrom. 14, 585-589.

Ikeda, S., Terazawa, T., Satake, H., and Hisano, T. (1972). Potentiometric argentimetric method for successive titration of sulfide and dissolved sulfur in polysulfide solutions. Talanta 19, 1650-1654. doi: 10.1016/00399140(72)80240-6

Kaneshiro, S. M., and Clark, D. S. (1995). Pressure effects on the composition and thermal behavior of lipids from the deep-sea thermophile Methanococcus jannaschii. J. Bacteriol. 177, 3668-3672.

Lai, D., Springstead, J., and Monbouquette, H. (2008). Effect of growth temperature on ether lipid biochemistry in Archaeoglobus fulgidus. Extremophiles 12, 271-278. doi: 10.1007/s00792-007-0126-6

Langworthy, T., Mayberry, W. R., and Smith, P. F. (1974). Long-chain glycerol diether and polyol dialkyl glycerol triether lipids of Sulfolobus acidocaldarius. J. Bacteriol. 119, 106-116.

Langworthy, T., Smith, P. F., and Mayberry, W. R. (1972). Lipids of Thermoplasma acidophilum. J. Bacteriol. 112, 1193-1200.

Langworthy, T. A. (1982). Lipids of archaebacteria - extreme halophiles, methanogens and thermoacidophiles. J. Am. Oil Chem. Soc. 59, A285-A285.

Lanyi, J. K., Plachy, W. Z., and Kates, M. (1974). Lipid interactions in membranes of extremely halophilic bacteria. II. Modification of the bilayer structure by squalene. Biochemistry 13, 4914-4920.

Lanzotti, V., Trincone, A., Nicolaus, B., Zillig, W., Rosa, M. D., and Gambacorta, A. (1989). Complex lipids of Pyrococcus and AN1, thermophilic members of archaebacteria belonging to Thermococcales. Biochim. Biophys. Acta Lipids Lipid Metabol. 1004, 44-48. doi: 10.1016/0005-2760(89)90210-5

Lattuati, A., Guezennec, J., Metzger, P., and Largeau, C. (1998). Lipids of Thermococcus hydrothermalis, an Archaea isolated from a deep-sea hydrothermal vent. Lipids 33, 319-326. doi: 10.1007/s11745-998-0211-0

Lee, A. G. (2003). Lipid-protein interactions in biological membranes: a structural perspective. Biochim. Biophys. Acta 1612, 1-40. doi: 10.1016/S00052736(03)00056-7

Lee, A. G. (2004). How lipids affect the activities of integral membrane proteins. Biochim. Biophys. Acta 1666, 62-87. doi: 10.1016/j.bbamem.2004.0 5.012

Marr, A. G., and Ingraham, J. L. (1962). Effect of temperature on composition of fatty acids in Escherichia coli. J. Bacteriol. 84, 1260-1267.

Marteinsson, V. T., Birrien, J. L., Reysenbach, A. L., Vernet, M., Marie, D., Gambacorta, A., et al. (1999). Thermococcus barophilus sp. nov., a new barophilic and hyperthermophilic archaeon isolated under high hydrostatic pressure from a deep-sea hydrothermal vent. Int. J. Syst. Bacteriol. 49, 351-359. doi: 10.1099/00207713-49-2-351

Mathai, J. C., Sprott, G. D., and Zeidel, M. L. (2001). Molecular mechanisms of water and solute transport across archaebacterial lipid membranes. J. Biol. Chem. 276, 27266-27271. doi: 10.1074/jbc.M103265200

Matsuno, Y., Sugai, A., Higashibata, H., Fukuda, W., Ueda, K., Uda, I., et al. (2009). Effect of growth temperature and growth phase on the lipid composition of the archaeal membrane from Thermococcus kodakaraensis. Biosci. Biotechnol. Biochem. 73, 104-108. doi: 10.1271/bbb.80520

Meador, T., Gagen, E., Loscar, M., Goldhammer, T., Yoshinaga, M., Wendt, J., et al. (2014). Thermococcus kodakarensis modulates its polar membrane lipids and elemental composition according to growth stage and phosphate availability. Front. Microbiol. 5:10. doi: 10.3389/fmicb.2014.00010 
Minegishi, H., Echigo, A., Nagaoka, S., Kamekura, M., and Usami, R. (2010). Halarchaeum acidiphilum gen. nov., sp. nov., a moderately acidophilic haloarchaeon isolated from commercial solar salt. Int. J. Syst. Evol. Microbiol. 60, 2513-2516. doi: 10.1099/ijs.0.013722-0

Nichols, D. S., Miller, M. R., Davies, N. W., Goodchild, A., Raftery, M., and Cavicchioli, R. (2004). Cold adaptation in the Antarctic archaeon Methanococcoides burtonii involves membrane lipid unsaturation. J. Bacteriol. 186, 8508-8515. doi: 10.1128/jb.186.24.8508-8515.2004

Nishihara, M., and Koga, Y. (1987). Extraction and composition of polar lipids from the archaebacterium, Methanobacterium thermoautotrophicum : effective extraction of tetraether lipids by an acidified solvent. J. Biochem. 101, 997-1005.

Oger, P., and Cario, A. (2013). Adaptation of the archaeal membrane. Biophys. Chem. 15, 42-56. doi: 10.1016/j.bpc.2013.06.020

Pitcher, A., Hopmans, E. C., Mosier, A. C., Park, S.-J., Rhee, S.-K., Francis, C. A., et al. (2011). Core and intact polar glycerol dibiphytanyl glycerol tetraether lipids of ammonia-oxidizing Archaea enriched from marine and estuarine sediments. Appl. Environ. Microbiol. 77, 3468-3477. doi: 10.1128/aem.02 758-10

Russell, N. J., and Nichols, D. S. (1999). Polyunsaturated fatty acids in marine bacteria - a dogma rewritten. Microbiology 145, 767-779. doi: 10.1099/13500872-145-4-767

Schouten, S., Hopmans, E. C., Pancost, R. D., and Damsté, J. S. S. (2000). Widespread occurrence of structurally diverse tetraether membrane lipids: evidence for the ubiquitous presence of low-temperature relatives of hyperthermophiles. Proc. Natl. Acad. Sci. U.S.A. 97, 14421-14426. doi: 10.1073/pnas.97.26.14421

Sinensky, M. (1971). Temperature control of phospholipid biosynthesis in Escherichia coli. J. Bacteriol. 106, 449-455.

Sinensky, M. (1974). Homeoviscous adaptation - a homeostatic process that regulates the viscosity of membrane lipids in Escherichia coli. Proc. Natl. Acad. Sci. U.S.A. 71, 522-525. doi: 10.1073/pnas.71.2.522

Smeller, L. (2002). Pressure-temperature phase diagrams of biomolecules. Biochim. Biophys. Acta 1595, 11-29. doi: 10.1016/s0167-4838(01)00332-6

Sprott, G. D., Meloche, M., and Richards, J. C. (1991). Proportions of diether, macrocyclic diether, and tetraether lipids in Methanococcus jannaschii grown at different temperatures. J. Bacteriol. 173, 3907-3910.

Sugai, A., Masuchi, Y., Uda, I., Itoh, T., and Itoh, Y. (2000). Core lipids of hyperthermophilic archaeon. Pyrococcus horikoshii OT3. J. Jpn. Oil Chem. Soc. 49, 695-700. doi: 10.5650/jos1996.49.695

Sugai, A., Uda, I., Itoh, Y. H., and Itoh, T. (2004). The core lipid composition of the 17 strains of hyperthermophilic Archaea. Thermococcales. J. Oleo Sci. 53, 41-44. doi: 10.5650/jos.53.41
Tornabene, T. G. (1978). Non-aerated cultivation of Halobacterium cutirubrum and its effect on cellular squalenes. J. Mol. Evol. 11, 253-257. doi: 10.1007/bf01734486

Trincone, A., Nicolaus, B., Palmieri, G., De Rosa, M., Huber, R., Huber, G., et al. (1992). Distribution of complex and core lipids within new hyperthermophilic members of the Archaea domain. Syst. Appl. Microbiol. 15, 11-17. doi: 10.1016/S0723-2020(11)80130-X

van Meer, G., Voelker, D. R., and Feigenson, G. W. (2008). Membrane lipids: where they are and how they behave. Nat. Rev. Mol. Cell Biol. 9, 112-124. doi: $10.1038 / \mathrm{nrm} 2330$

Villanueva, L., Damsté, J. S. S., and Schouten, S. (2014). A re-evaluation of the archaeal membrane lipid biosynthetic pathway. Nat. Rev. Microbiol. 12, 438-448. doi: 10.1038/nrrnicro3260

Winter, R. (2002). Synchrotron X-ray and neutron small-angle scattering of lyotropic lipid mesophases, model biomembranes and proteins in solution at high pressure. Biochim Biophys Acta 1595, 160-184. doi: 10.1016/s01674838(01)00342-9

Wirsen, C. O., Jannasch, H. W., Wakeham, S. G., and Canuel, E. A. (1986). Membrane lipids of a psychrophilic and barophilic deep-sea bacterium. Curr. Microbiol. 14, 319-322. doi: 10.1007/BF01568697

Xue, Y. F., Fan, H. P., Ventosa, A., Grant, W. D., Jones, B. E., Cowan, D. A., et al. (2005). Halalkalicoccus tibetensis gen. nov., sp nov., representing a novel genus of haloalkaliphilic Archaea. Int. J. Syst. Evol. Microbiol. 55, 2501-2505. doi: 10.1099/ijs.0.63916-0

Yayanos, A. A. (1986). Evolutional and ecological implications of the properties of deep-sea barophilic bacteria. Proc. Natl. Acad. Sci. U.S.A. 83, 9542-9546. doi: 10.1073/pnas.83.24.9542

Zeng, X., Birrien, J. L., Fouquet, Y., Cherkashov, G., Jebbar, M., Querellou, J., et al. (2009). Pyrococcus CH1, an obligate piezophilic hyperthermophile: extending the upper pressure-temperature limits for life. ISME J. 3, 873-876. doi: 10.1038 /ismej.2009.21

Conflict of Interest Statement: The authors declare that the research was conducted in the absence of any commercial or financial relationships that could be construed as a potential conflict of interest.

Copyright (c) 2015 Cario, Grossi, Schaeffer and Oger. This is an open-access article distributed under the terms of the Creative Commons Attribution License (CC BY). The use, distribution or reproduction in other forums is permitted, provided the original author(s) or licensor are credited and that the original publication in this journal is cited, in accordance with accepted academic practice. No use, distribution or reproduction is permitted which does not comply with these terms. 